\title{
sciendo
}

\author{
RESEARCH PAPERS FACULTY OF MATERIALS \\ SCIENCE AND TECHNOLOGY IN TRNAVA \\ SLOVAK UNIVERSITY OF TECHNOLOGY \\ IN BRATISLAVA
}

2018, Volume 26, Number 42

DOI 10.2478/rput-2018-0002

\section{FIRE RISK OF HALOGEN-FREE ELECTRICAL CABLE}

\author{
Jozef MARTINKA, Peter RANTUCH, Igor WACHTER, Karol BALOG \\ SLOVAK UNIVERSITY OF TECHNOLOGY IN BRATISLAVA \\ FACULTY OF MATERIALS SCIENCE AND TECHNOLOGY IN TRNAVA \\ INSTITUTE OF INTEGRATED SAFETY \\ Ulica JÁna BotTu 2781/25, 91724 TRNAVA, SlovaK REPUBliC \\ e-mail: jozef.martinka@stuba.sk, peter.rantuch@stuba.sk,igor.wachter@stuba.sk, \\ karol.balog@stuba.sk \\ Received: 23.04.2018, Accepted: 02.07.2018, Published: 19.09.2018
}

\begin{abstract}
This paper deals with the fire risk of a selected halogen-free electrical cable. The research was objected to a three-core power electric cable for a fixed installation CHKE J3x1.5 (cross section of each copper core was $1.5 \mathrm{~mm}^{2}$ ) with a declared class of reaction to fire $B 2_{c a}, s 1, d 1$, al. The electrical cable was manufactured and supplied by VUKI, a. s., Slovakia. The fire risk of the electric cable was evaluated based on the heat release rate, total heat release, smoke release rate, total smoke release and effective heat of combustion. These parameters were measured using a cone calorimeter at $50 \mathrm{~kW} \mathrm{~m}^{-2}$ (specimens and cone emitter were placed horizontally during the test). The measured electrical cable showed a maximum heat release rate of nearly $150 \mathrm{~kW} \mathrm{~m}^{-2}$, a maximum average heat emission rate of almost $100 \mathrm{~kW} \mathrm{~m}^{-2}$, a total heat release of almost $130 \mathrm{MJ} \mathrm{m}^{-2}$, a maximum smoke release rate of almost $2.5 \mathrm{~s}^{-1}$, a total smoke release of more than $800 \mathrm{~m}^{2} \mathrm{~m}^{-2}$, an effective heat of combustion (cable as a whole) of nearly $9 \mathrm{MJ} \mathrm{kg}^{-1}$ and an effective heat of emission (polymeric parts of the cable) of $26.5 \mathrm{MJ} \mathrm{kg}^{-1}$.
\end{abstract}

\section{Key words}

Cone calorimeter, electrical cables, fire risk, halogen-free, reaction to fire class

\section{INTRODUCTION}

Electrical cables are classified according to EN 13501-6:2018 based on test results according to EN ISO 1716:2018, EN 60332-1-2:2004, EN 50399:2011, EN 61034-2:2005 and EN 50267-2-3:1998, which has been replaced in its entirety by a technical standard EN 607542:2014 into seven classes of reaction to fire $\mathrm{A}_{\mathrm{ca}}, \mathrm{B} 1_{\mathrm{ca}}, \mathrm{B} 2_{\mathrm{ca}}, \mathrm{C}_{\mathrm{ca}}, \mathrm{D}_{\mathrm{ca}}, \mathrm{E}_{\mathrm{ca}}$ a $\mathrm{F}_{\mathrm{ca}}$, four additional smoke classification classes s1, s1a, s1b a s2, three additional classifications for burning droplets $\mathrm{d} 0, \mathrm{~d} 1 \mathrm{a} \mathrm{d} 2$ and three additional classifications on the acidity of combustion products a1, a2 a a3. The additional classification is determined only for electrical cables with reaction class to fire from $\mathrm{B} 1_{\text {ca }}$ to $\mathrm{D}_{\text {ca. }}$. The contribution of a cable to fire development increases from 
the reaction to fire class from $\mathrm{A}_{\mathrm{ca}}$ (no or negligible contribution to the development of the fire) to $\mathrm{F}_{\mathrm{ca}}$ (maximum contribution to fire development). Likewise, the formation of smoke, flaming droplets and the acidity of the combustion products (trapped in distilled or demineralized water) increases with the increasing number of supplementary classification.

For the classification of the electrical cable in the reaction to fire class, it is necessary to measure combustion heat according to EN ISO 1716:2018 (reaction class to fire $A_{c a}$ ), the total heat release, maximum heat release rate, parameter FIGRA (Fire Growth Rate Index) and vertical flame spread according to EN 50399:2011 (reaction classes to fire from B $1_{\text {ca }}$ to $\mathrm{D}_{\mathrm{ca}}$; for the class $D_{c a}$ it is not necessary to measure vertical flame spread) and vertical flame spread according to EN 61034-2:2005 (reaction classes to fire from $\mathrm{B} 1_{\mathrm{ca}}$ to $\mathrm{E}_{\mathrm{ca}}$ ). For the classification of the electrical cable in the additional smoke classification, it is necessary to measure the total smoke release, the maximum smoke release rate according to EN 50399:2011 and the light transmission (through combustion products) according to EN 61034-2:2005. To classify the electrical cable into the additional classification for burning droplets, it is necessary to measure the burning droplets according to EN 50399:2011. To classify the electrical cable in the additional classification for the acidity of the combustion products, the $\mathrm{pH}$ and conductivity of the distilled or demineralized water to which the combustion products are retained according to EN 60754-2:2014 need to be measured.

The reaction to fire of other construction products and building elements (other than electrical cables) is in more detail described in the paper by Mitterova et al. (2004).

In compartments with high fire risk for persons (especially escape routes), STN 92 0203:2013 requires to use cables with a reaction-to-fire class $\mathrm{B} 2_{\mathrm{ca}}, \mathrm{s} 1$, a1, s1. The cable with the mentioned fire reaction class is therefore considered to be the standard for fire hazard areas in the Slovak Republic but also in some other European Union Member States.

Although the cables are classified in the fire reaction classes, it is necessary to know, in particular, the heat release rate, the total heat release, the heat of combustion, the rate of smoke release and the total smoke release determined under conditions comparable to those of the other solid materials. The aim of this scientific paper is therefore to determine the heat release rate, the total heat release, effective heat of combustion, the rate of smoke release, and the total smoke release from the selected non-halogen electrical cable with the fire reaction class of $\mathrm{B} 2 \mathrm{ca}$, s1, a1, s1 using a cone calorimeter.

\section{MATERIALS AND METHODOLOGY OF EXPERIMENT}

The research was objected to a three-core power electric (halogen-free) cable for a fixed installation designated as CHKE J3x1.5. The cable was manufactured and supplied by VUKI, a. s., Slovak Republic. The investigated electrical cable consisted of three insulated copper wires and other sheath. The space between the insulated conductors and the sheath was filled with bedding. The copper wires were wrapped under the insulation with mica tape. The copper conductors were $1.5 \mathrm{~mm}^{2}$ thick in cross-section. Insulated copper conductors and electrical cable sheathing were made of ethylene-based polymer. The bedding between the insulated electric conductors and the sheath was made of an ethylene-based polymer with a high content of inorganic fillers (metal hydroxides and chalk). The diameter of the insulated electric conductors constituting the electrical cable was $3 \mathrm{~mm}$ thick and the diameter of the electrical cable was $9 \mathrm{~mm}$ thick. The manufacturer declared the fire reaction class of the investigated electrical cable to be $\mathrm{B} 2_{\mathrm{ca}}, \mathrm{s} 1, \mathrm{~d} 1$, a1. The cross section of the examined electric cable is shown in Fig. 1.

The samples were tested by a cone calorimeter according to the ISO 5660-1:2015 technical standard. The test procedure was also set up according to the ISO 5660-1:2015 standard. Orientation of the samples to the cone emitter was horizontal. The samples were thermally 
loaded by a heat flux of $50 \mathrm{~kW} \mathrm{~m}^{-2}$ during the test. The duration of the test was 30 minutes in accordance with the ISO 5660-1:2015. ARHE (Average Rate of Heat Emission) was calculated from data measured by cone calorimeter (heat release rate) by the method of Zhang (2008). The Maximum Average Rate of Heat Emission (MARHE) was set as the maximum value of ARHE.

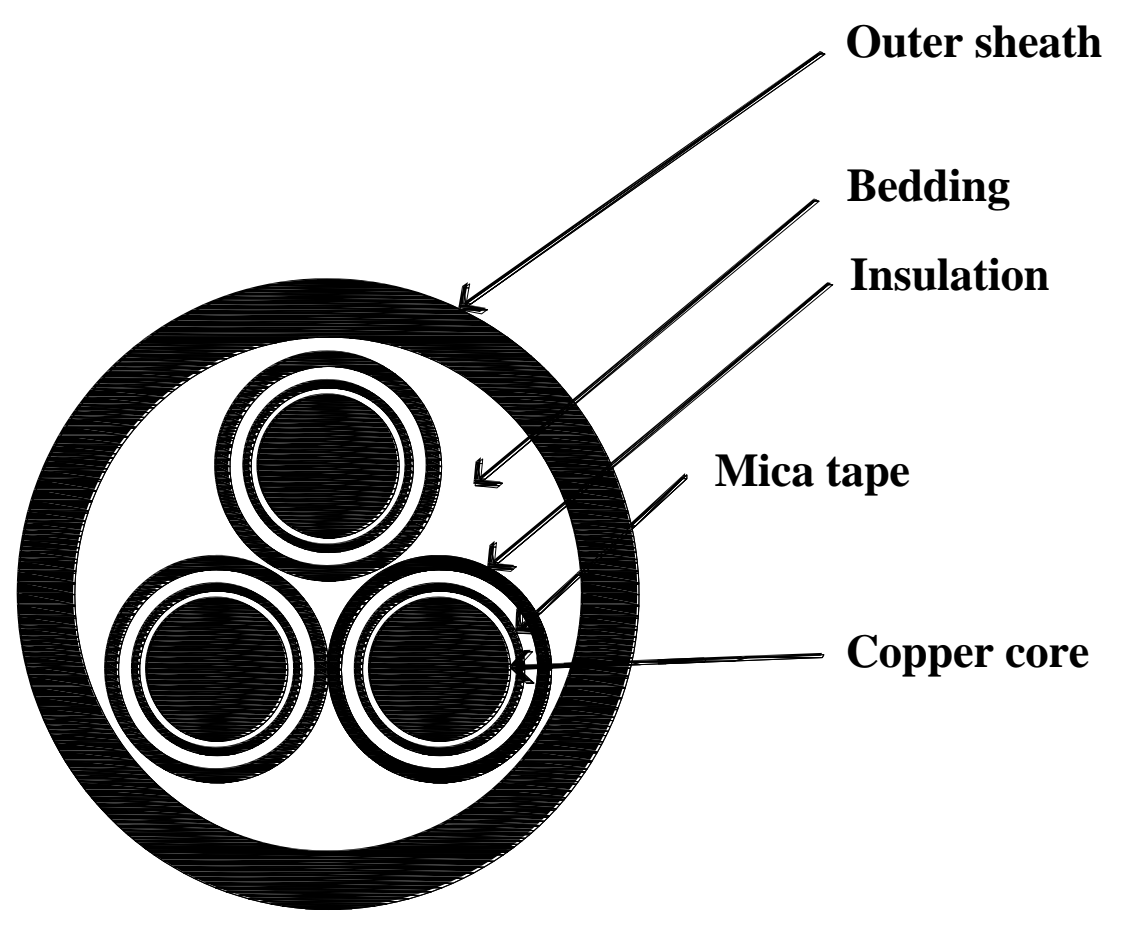

Fig. 1 The cross section of the investigated CHKE-V J3x1.5 electrical cable

\section{RESULTS AND DISCUSSION}

The heat release rate and the total heat release from the measured cable are shown in Fig. 2. In Fig. 2, two approximately the same local maxima were identified. The first local maximum corresponded approximately to the moment of initiation, while the second local maximum was recorded just before the complete burnout of the polymeric components of the investigated electrical cable. The cause of the second local maximum was probably overheating of the samples. This conclusion is consistent with the results of scientific work by Schartel et al. (2005) and Carvel (2011). 


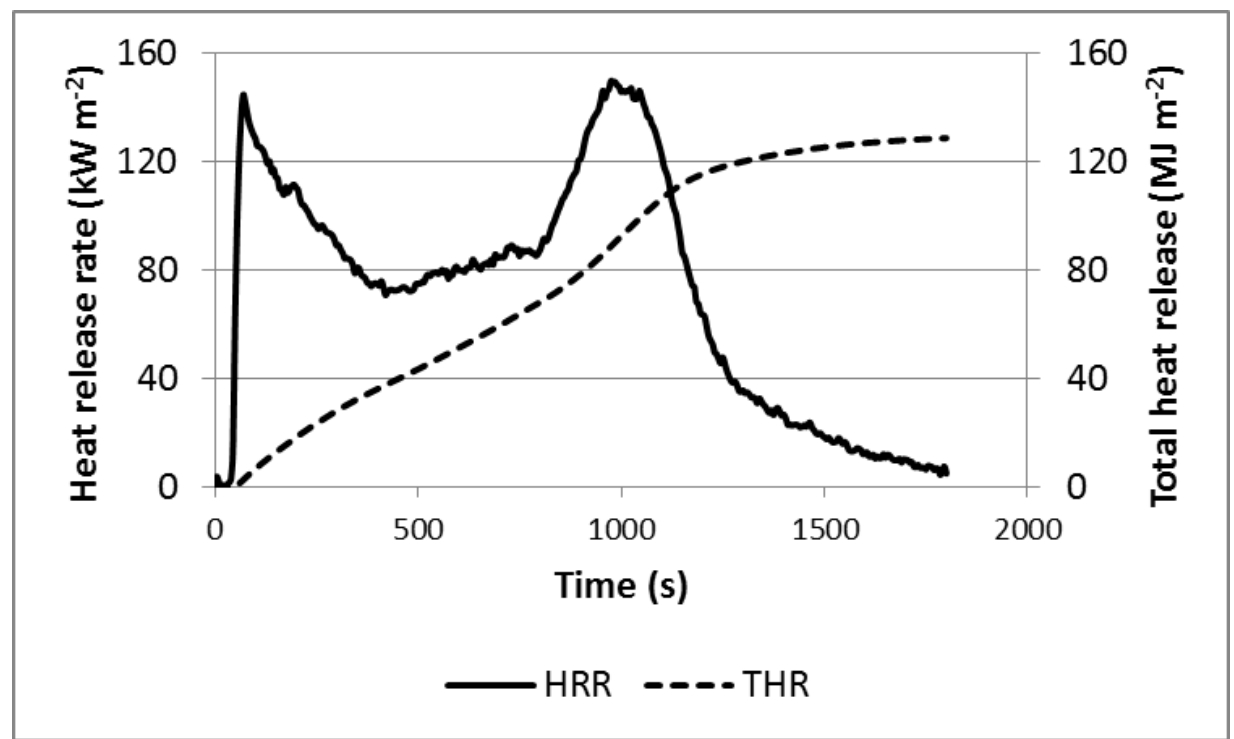

Fig. 2 Heat release rate and total heat release of halogen-free electrical cable CHKE-V thermally loaded by heat flux of $50 \mathrm{~kW} \mathrm{~m}^{-2}$

The maximum heat release rate (approximately $150 \mathrm{~kW} \mathrm{~m}^{-2}$ in Fig. 2) is roughly consistent with the results published by Witkowski et al. (2012), according to which ethylene-vinyl acetate filled with metal hydroxides (a material used for the manufacture of halogen-free electrical cables) shows a maximum heat release rate of approximately $170 \mathrm{~kW} \mathrm{~m}^{-2}$ (under conditions identical to those used in this scientific work).

Significant decrease in the heat release rate in Fig. 2 (during a time interval of 1,000 to $1,500 \mathrm{~s}$ ) was caused by the complete burnout of the polymer components of the tested electric cable. This conclusion was confirmed also by Fig. 3, which clearly demonstrates that the mass of the measured electric cable drops very slowly in the time interval from 1,500 s to $1,800 \mathrm{~s}$ (end of test). The residual mass of the examined cable represents the mass of copper wires and inorganic fillers (mainly used in the filler).

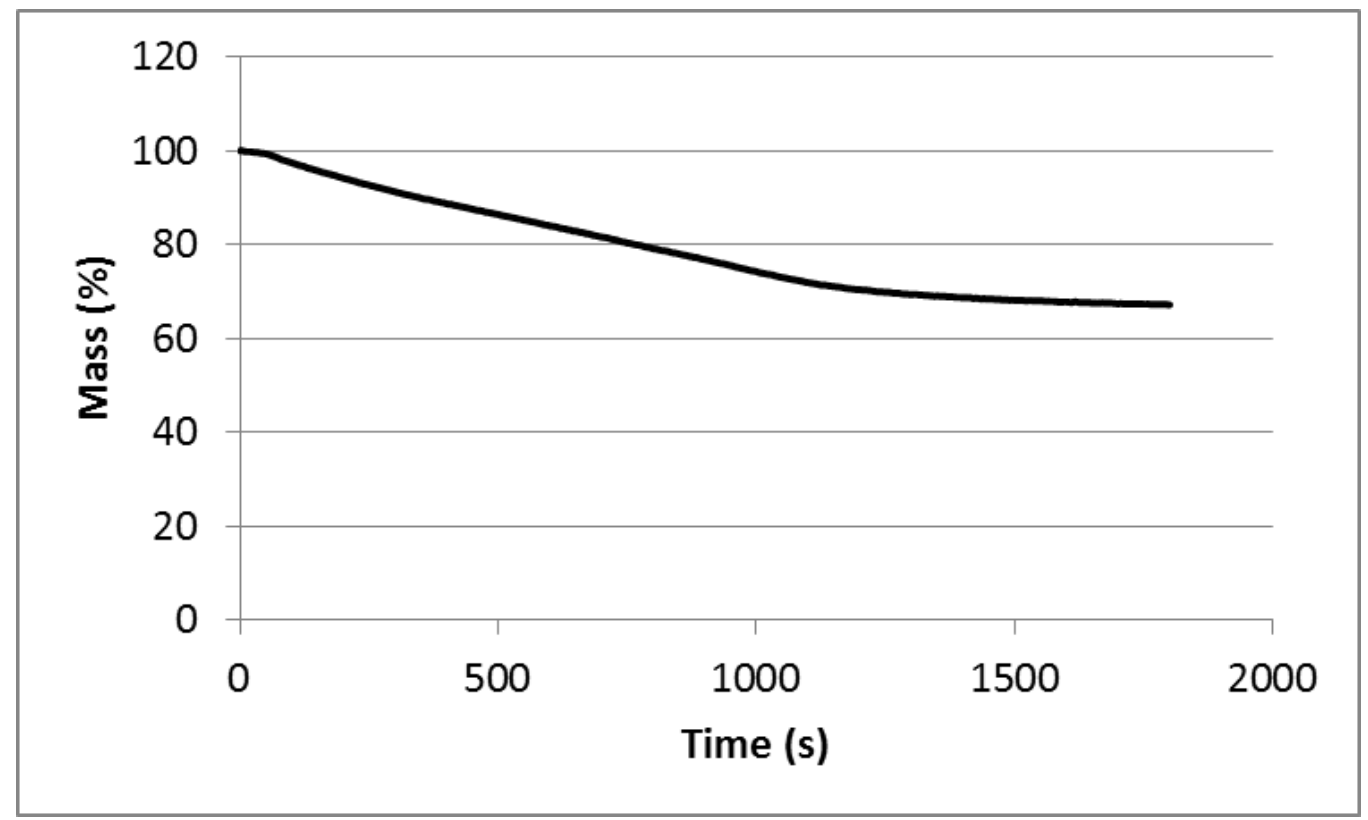

Fig. 3 The time dependence of mass of halogen-free electrical cable CHKE-V thermally loaded by heat flux of $50 \mathrm{~kW} \mathrm{~m}^{-2}$ 
From the obtained data of total heat release, initial sample mass and sample mass loss, the effective heat of combustion of the electrical cable as a whole and the effective heat of combustion of the polymeric parts of the electric cable were calculated. The effective heat of combustion of the electrical cable as a whole $\left(8.9 \mathrm{MJ} \mathrm{kg}^{-1}\right)$ was calculated from the released heat and from the initial mass of the sample. The application of this effective heat of combustion is mainly in the calculation of fire load; because it is sufficient to know the origin of mass of cables (it is not necessary to know the mass ratio of inorganic and organic components of the electric cable). The effective heat of combustion of polymeric parts of the electrical cable (26.5 MJ $\mathrm{kg}^{-1}$ ) was calculated from the released heat and from the mass loss of the sample. The application of this effective heat of combustion is primarily in modelling fires.

Reference material in the fire safety of structures is considered to be wood. According to Gunther et al. (2012) an effective heat of combustion of wood is $17.41 \pm 0.67 \mathrm{MJ} \mathrm{kg}^{-1}$ and according to Martinka et al. (2018) it is $17.84 \pm 0.17 \mathrm{MJ} \mathrm{kg}^{-1}$. The measured electrical cable (as a whole) therefore shows lower effective heat of combustion than the reference material in the field of fire safety of structures.

The average rate of heat emission (ARHE) from the measured cable is shown in Fig. 4. Although ARHE (Fig. 4) had a more uniform course than the rate of heat release (Fig. 2), it was still possible to identify two local maxima in time dependence. The maximum average rate of heat emission (MARHE) of the measured cable was nearly $100 \mathrm{~kW} \mathrm{~m}^{-2}$ (Fig. 4). This value was lower than MARHE of wood and wood-based materials in the scientific work of Carosio et al. (2016).

The specific smoke production rate and the total smoke release are shown in Fig. 5. The specific smoke production rate was that of a unit $\mathrm{m}^{2} \mathrm{~m}^{-2} \mathrm{~s}^{-1}$. This unit simply quantifies the area of the light beam (in $\mathrm{m}^{2}$ ) which overshadows the amount of released smoke from the area of one square meter (measured cable) per second. The total smoke release was that of a unit $\mathrm{m}^{2} \mathrm{~m}^{-}$ ${ }^{2}$. This unit simply quantifies the area of the light beam (in $\mathrm{m}^{2}$ ) which overshadows the amount of released smoke from one $\mathrm{m}^{2}$ area (measured cable) from the start of the test. Similar ideas are expressed, for example, by Ostman (2009).

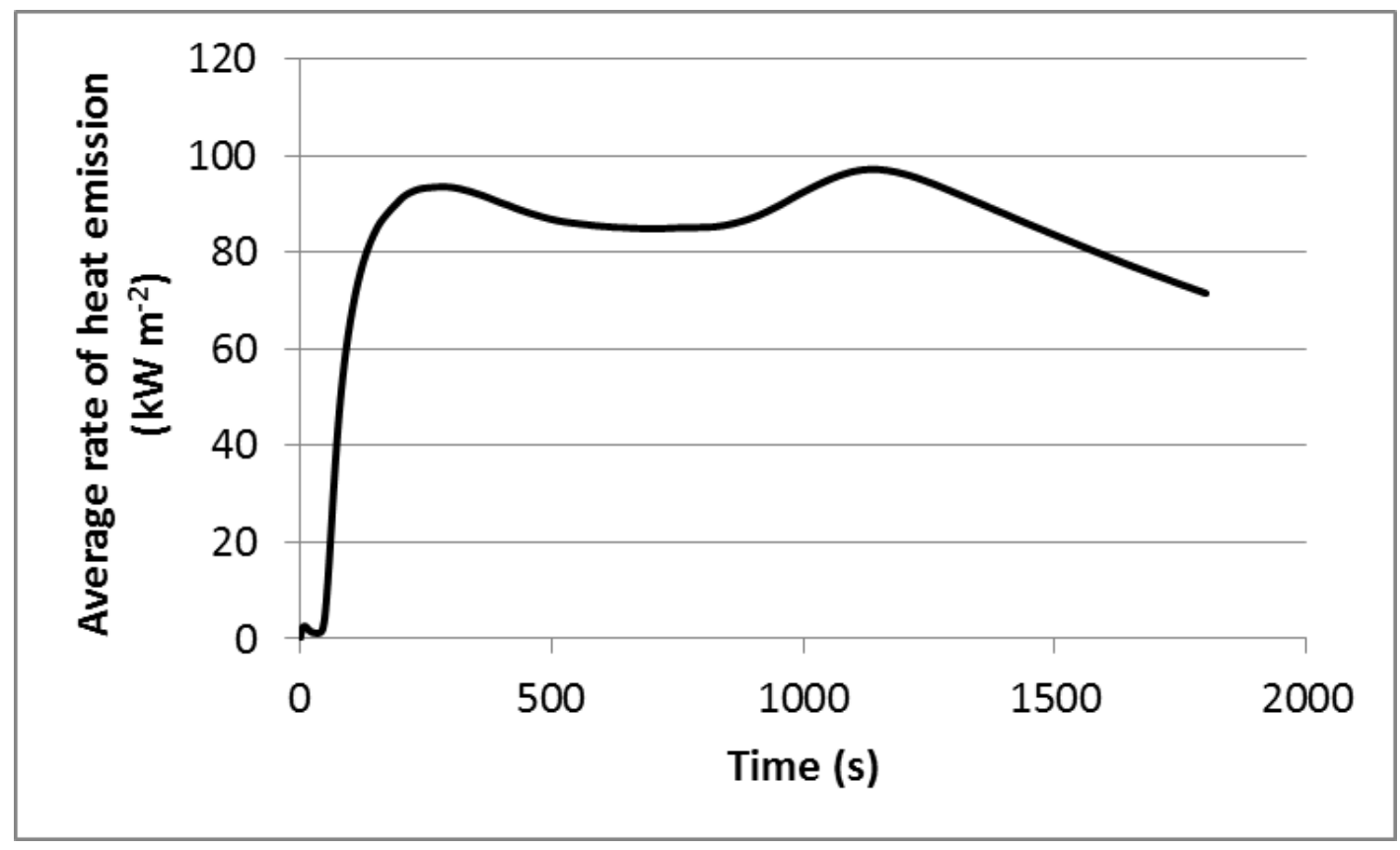

Fig. 4 Average rate of heat emission of CHKE-V cable thermally loaded by a $50 \mathrm{~kW} \mathrm{~m}^{-2}$ 


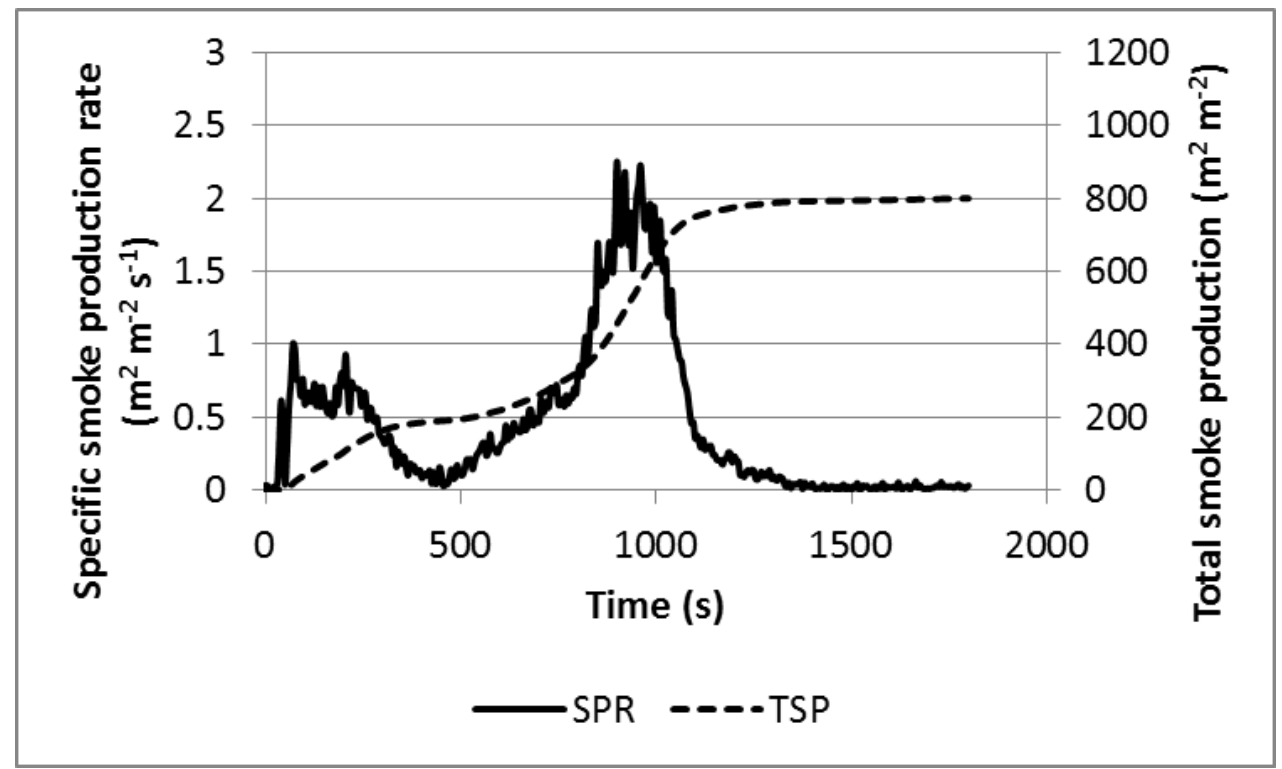

Fig. 5 Specific smoke release rate and total smoke production of CHKE-V cable loaded by $50 \mathrm{~kW} \mathrm{~m}^{-2}$

Comparison of the total smoke production (Fig. 5) with the Martinka's (2017) research shows that the investigated electrical cable exhibits a higher total smoke production than lignocellulosic materials.

\section{CONCLUSION}

In the scientific research, the fire risk of a halogen-free electric cable with the reaction to fire class $\mathrm{B} 2_{\mathrm{ca}}, \mathrm{s} 1, \mathrm{~d} 1$, a1 (which according to valid technical regulations can be used in the Slovak Republic in areas with the highest threat to persons - especially escape routes) was investigated. The fire risk was evaluated based on the heat release rate, effective heat of combustion and specific smoke production rate. The obtained data showed that the investigated halogen-free electrical cable showed a lower maximum heat release rate, lower effective heat of combustion (electrical cable as a whole), and a higher specific smoke release rate as a reference material in the fire safety of constructions (wood).

\section{Acknowledgements}

This contribution was supported by the Slovak Research and Development Agency under the contract No. APVV-16-0223.

\section{References:}

1. CAROSIO, F., CUTTICA, F., MEDINA, L., BERGLUND, L., A. 2016. Clay nanopaper as multifunctional brick and mortar fire protection coating-Wood case study. In: Materials and Design, 93(1), pp. 357-363.

2. CARVEL, R., STEINHAUS, T., REIN, G., TORERO, J., L. 2011. Determination of the flammability properties of polymeric materials: a novel method. In: Polymer Degradation and Stability, 96(3), pp. 314-319.

3. EN 13501-6:2018. Fire classification of construction products and building elements. Part 6: Classification using data from reaction to fire tests on electric cables.

4. EN 50399:2011. Common test methods for cables under fire conditions. Heat release and smoke production measurement on cables during flame spread test. Test apparatus, procedures, results. 
5. EN 50267-2-3:1998. Common test methods for cables under fire conditions. Tests on gases evolved during combustion of materials from cables. Part 2-3: Procedures. Determination of degree of acidity of gases for cables by determination of the weighted average of $\mathrm{pH}$ and conductivity.

6. EN 60332-1-2:2004. Tests on electric and optical fibre cables under fire conditions. Part 1-2: Test for vertical flame propagation for a single insulated wire or cable. Procedure for $1 \mathrm{~kW}$ pre-mixed flame.

7. EN 60754-2:2014. Fire Test on gases evolved during combustion of materials from cables. Part 2: Determination of acidity (by $\mathrm{pH}$ measurement) and conductivity.

8. EN 61034-2:2005. Measurement of smoke density of cables burning under defined conditions. Part 2: Test procedure and requirements.

9. EN ISO 1716:2018. Reaction to fire tests for products. Determination of the gross heat of combustion (calorific value).

10. GUNTHER, B., GEBAUER, K., BARKOWSKI, R., ROSENTHAL, M., BUES, C., T. 2012. Calorific value of selected wood species and wood products. In: European Journal of Wood and Wood Products, 70(5), pp. 755-757.

11. ISO 5660-1:201 Reaction to fire tests. Heat release, smoke production and mass loss rate. Part 1: Heat release rate (cone calorimeter method) and smoke production rate (dynamic measurement).

12. Martinka 2016

13. MARTINKA, J., MARTINKA, F., RANTUCH, P., HRUŠOVSKÝ, I., BLINOVÁ, L., BALOG, K. 2018. Calorific value and fire risk of selected fast-growing wood species. In: Journal of Thermal Analysis and Calorimetry, 131(2), pp. 899-906.

14. MARTINKA, J., RANTUCH, P., BALOG, K. 2017. Fire hazard and heat of combustion of sunflower seed hull pellets. In: Journal of Thermal Analysis and Calorimetry, 130(3), pp. 15311540 .

15. MITTEROVA, I., ZACHAR, M., RUZINSKA, E., MAJLINGOVA, A. 2004. Ignitability of unprotected and retardant protected samples of spruce wood. In: Advanced Materials Research, 1001(1), pp. 330-335.

16. OSTMAN, B., A., L. 2009. Smoke and soot. In: Babrauskas, V., Grayson, S., J., editors. Heat release in fires. 2nd ed. Hampshire: Interscience communications, pp. 233-250.

17. SCHARTEL, B., BARTHOLMAI, M., KNOLL, U. 2005. Some comments on the use of cone calorimeter data. In: Polymer Degradation and Stability, 88(3), pp. 540-547.

18. STN 92 0203:2013 Fire protection of buildings. Continuous power supply responding for fire.

19. WITKOWSKI, A., HOLLINGBERRY, L., HULL, R., T. 2012. Fire retardancy of mineral fillers in EVA copolymers. In: Morgan, A., B., Wilkie, C., A., Nelson, G., L., editors. ACS symposium series 1118, fire and polymers VI: new advances in flame retardant chemistry \& science. Washington: American Chemical Society, pp. 97-111.

20. ZHANG, J. 2008. Study of polyamide 6-based nanocomposites. New York: Polytechnic University.

\section{ORCID:}

$\begin{array}{ll}\text { Jozef Martinka } & 0000-0002-0060-5785 \\ \text { Peter Rantuch } & \text { 0000-0001-5826-8323 } \\ \text { Karol Balog } & 0000-0002-0804-8338\end{array}$

